\title{
Ruptura y modernidad. La renovación de los estereotipos en la Argentina de los años 20: El juguete rabioso de Roberto Arlt
}

\author{
Sol Villaceque \\ Centre d'Études et de Recherches Sociocritiques \\ Montpellier, Francia
}

\section{Un texto inaugural de una nueva práctica escritural en la Argen- tina de la mezcolanza ${ }^{\mathrm{l}}$}

[...] El texto en el que se basa mi análisis, El juguete rabioso, rubricó en 1926 el acto de nacimiento de la narrativa urbana rioplatense [...]. Es un texto fundador y anticipador de toda una tradición rioplatense de literatura aluvional.

El choque emocional y la extrañeza que produce la lectura de la novela procede en parte de la mezcolanza de discursos y lenguajes que presenta el texto. Ese gesto, considerado como un crimen de lesa literatura y una insoportable trivialidad, es responsable, entre otras infracciones, de la tenaz leyenda de la "mala escritura" de R.A. Con

1. Este artículo se inscribe en la reflexión llevada a cabo en el seminario organizado por el Instituto Internacional de Sociocrítica, en el que se analizaron algunas formas de la modernidad urbana surgidas en las primeras décadas del siglo XX. Se ha acudido a las siguientes abreviaturas: R.A.: RobertoArlt; EJR: El juguete rabioso; O.C.: Obra completa de Roberto Arlt (Buenos Aires: Planeta/Carlos Lohlé, 1991), tres tomos; $\boldsymbol{F} M$ : Las flores del mal de Charles Baudelaire, Oeuvres Complètes (París: Laffont, 1992); DRAE: Diccionario de la Lengua Española de la Real Academia Española. En cuanto a las citas, en el texto de Arlt la paginación corresponde a la edición de Losada, Buenos Aires, 1991; y en todos los textos citados el subrayado es mío, salvo cuando se especifica que pertenece al original. 
cuarenta años de anticipación respecto de la primera novela de Manuel Puig, se nos ofrece un texto que asume la heterogeneidad como principio de su composición.

En este trabajo de exploración de uno de los niveles lingüísticos del texto arltiano, he tratado de analizar las manifestaciones fenotextuales producidas a raíz de la invasión masiva de fragmentos discursi vos procedentes de la paraliteratura y de observar el trabajo morfogenético que realiza la escritura a raíz de esa confrontación.

Previamente, presentaré y definiré el material que el criterio jerárquico pretende marginar.

\section{Especificidad y funcionalidad del arqueodiscurso}

\subsection{La hidra de la literatura}

Los estereotipos, tópicos o clichés suelen catalogarse como componentes desclasados del macrosistema literario de consumo de masas y, por tanto, se hallan confinados por la cultura consagrada en la otra zona: el ámbito del mal gusto. Pero ese discurso arcaico elaborado a partir de escrituras, retóricas e imaginarios al parecer gastados, tiene la paradójica aptitud de renacer incesantemente, cual la hidra mitológica, surgiendo a veces en el lugar donde menos se le esperaba, es decir, en los productos culturales que se precian de acosarlo y despreciarlo. Según la fórmula utilizada por Barthes en su Lección de 1978, "En cada signo duerme ese monstruo: el estereotipo".

La centralidad del concepto de estereotipo en la cultura contemporánea es significativa ${ }^{2}$. En Francia, la noción, que se fortalece en el siglo XVIII, suscitará en el siguiente una reflexión crítica por parte de los escritores (Flaubert, Rémy de Gourmont, entre otros), creándose en las últimas décadas del siglo XX una verdadera semiología del estereotipo.

2. Prueba de ello es el Simposio Internacional sobre el tema: Stéréotypes, Textes, Modernité, celcbrado en octubre de 1993 en Cerisy. 
En este trabajo se consideran las palabras estereotipo, cliché, tópico y lugar común como semánticamente próximas, sin entrar en los matices diferenciales que, por cierto, existen. El análisis del discurso académico y crítico sobre los estereotipos, presente por ejemplo en las definiciones de los diccionarios y textos de esa índole ${ }^{3}$, permite trazar un cuadro de la funcionalidad de este material estereotipado.

\subsection{Tipología funcional}

\subsubsection{Un discurso desclasado}

* Mimetismoy reproductibilidad: el arqueodiscurso emplea esquemas expresivos repetibles indefinidamente, plagiables y autoplagiables. * Trivialidad y banalidad: son formas degradadas, pervertidas por su uso repetido, encerradas en el mal gusto y la cursilería ${ }^{4}$.

* Un discurso muerto: está elaborado con "cadáveres" de palabras, cerrado al juego polisémico del lenguaje vivo. Reproduce formas fosilizadas, simples artefactos para fabricar productos en serie. * Convencionalidad y conformismo: M. Moliner recalca el empleo automático y la índole irreflexiva del uso de los estereotipos.

3. Cfr. DRAE (1956)-Estereotipia: "Repetición involuntaria e intempestiva de un gesto, acción o palabra. Ocurre principalmente en ciertos dementes". -Tópico: "Expresión vulgar o trivial". María Moliner (1983) -Estereotipado: "Se aplica a la expresión pluriverbal que tiene una forma fija con la cual se inserta en el lengua je sin formarla reflexivamente para cada caso". Cliché o lugar común: "Tópico. Vulgaridad. Idea vulgar y muy repetida" Robert (1985). — Stéréotype: "XX. Mod., didact. ou litt. Opinion toute faite, cliché, réduisant les singularités". El Robert presenta la definición de Gilbert Simondon: "Un stéréotype est une représentation à deux dimensions, comme une image sans profondeur et sans plasticité", en «Du mode d'existence des objets techniques». - Diccionario de retórica, crític a y terminología literaria, de Marchese y Forradellas (1989): "El cliché es un sintagma o una construcción expresiva en sus orígenes que se ha trivializado y codificado por frecuencia de su empleo [...], por desgaste de uso, pierde cualquier relieve y se automatiza"perdido cualquier connotación estilística que haya podido tener [...] es más bien lo convencional linguístico e ideológico".

4. Lo "cursi" procede del gesto mimético propio del uso de los clichés. Se observa particularmente en el lengua je y el comportamiento de aquellos que, desde una condición vivida como inferior, copian discursos que atribuyen a "los de arriba", derivándose de ello un desfase que la cultura superior tacha de "mal gusto" o "ridículo". 
Estas escorias del pasado reproducen esquemas que transmiten una ideología conservadora y reaccionaria de serias consecuencias culturales. Finalmente, son productos alienados (todo está supeditado a una meta: gustar a la masa semiculta y a la pequeña burguesía) y al mismo tiempo alienantes: se manipula a un público indefenso mediante ese "falso aire atrevido y coqueto", según la expresión del Littré, se alimenta su pobreza intelectual construyendo un mundo de proyecciones ingenuas, lejos de toda reflexión racionalizante y, por fin, se propalan modelos reaccionarios impuestos por la ideología dominante.

\subsubsection{Un discurso funcional y operativo}

- Un repertorio para facilitar la producción de textos (ver la definición de la tópica por el Robert como "un repertorio para facilitar la invención").

Estas formas, que fueron en su origen creaciones novedosas, luego se convirtieron en modelos prácticos usados de modo mecánico, en piezas para el juego de construcción literaria, o para los juegos convencionales del lenguaje conversacional.

- Éxito comercial de los modelos de identificación.

El material desgastado asegura el éxito comercial de los productos culturales que se construyen a partir de él (folletín literario, radio/ foto/telenovela, tango, bolero, entre otros), porque of recen al público ingenuo unos modelos emblemáticos de identificación. Este proceso identificatorio se halla precisamente facilitado por su radical impersonalidad, manejabilidad y reproducibilidad.

- El cliché, instrumento de comunicación.

El cliché permite evitar el peligro de la reflexión y de los encuentros más profundos: en el tango, por ejemplo, el cantante y su público dialogan y se comprenden en ausencia de todo cuestionamiento. Opera, en la novela rosa, la magia identificadora sin necesidad de profundizar. 


\section{Arqueodiscurso e intertextualidad: folletín, tango y literatu- ra rusa}

Antes de explorar los caminos de penetración en el texto de los estereotipos, abro un paréntesis. Para que los ejemplos sacados de $E J R$ sean significantes para los que no tengan bien memorizada la novela, quizás sea útil resumirla brevemente.

En esta narración autobiográfica con ribetes de picaresca, cuenta el narrador unos episodios de su adolescencia transcurridos entre los catorce y dieciséis años. Silvio Drodman Astier, iniciado a la literatura por la lectura de las "novelas por entregas" de famosos bandoleros andaluces y fervoroso admirador de las aventuras del popular Rocambole, realiza un recorrido iniciático a través de la Buenos Aires de los años 10. Hijo de inmigrantes de condición modesta, huérfano de padre y abandonado por la novia, crea con dos compañeros el «Club de los Caballeros de la Media Noche», lanzándose a una experiencia anarcoconspirativa, brutalmente interrumpida (Cap. I: «Los ladrones»). A continuación, fracasan también todos sus intentos de integración social por el trabajo para ayudar a su madre y a su hermana. Los empleos subalternos conseguidos transitoriamente ahondan cada día más su sentimiento de humillación y degradación (Cap. II: «Los trabajos y los días», Cap. III: «El juguete rabioso»). El insólito encuentro con un homosexual en un mísero conventillo desemboca en una tentativa de suicidio, que también aborta (Cap. III). En el último capítulo («Judas Iscariote») se clausura el descenso a las zonas tenebrosas de la abyección por un acto criminal: Silvio delata a su único amigo, el Rengo, traicionando así definitivamente la causa proletaria, y se pone bajo la protección paternalista de un hombre influyente. Entonces, misteriosamente, se produce una especie de resurrección del personaje, que se expresa por un himno a Dios, que es alegría.

Por vez primera en Argentina, en un texto perteneciente al género consagrado de la novela, se asiste a la irrupción de materiales 
alógenos procedentes de la zona periférica de la cultura. En la época de la escritura de $E J R$ el contexto cultural ha cambiado. Se desarrolla una nueva práctica social nacida en la Argentina del Primer Centenario. A raíz de las campañas de instrucción pública, se está popularizando la lectura y el sistema de producción popular masiva conoce un auge extraordinario.

Ahora bien, en un texto hipertextual y aluvional como el de R.A, resulta a veces difícil localizar el origen de algunos de los numerosos clichés y tópicos recuperados. Sin embargo, la mayoría de ellos parecen llegar a través de tres de los intertextos más presentes: las aventuras folletinescas, el tango-canción y los novelistas rusos popularizados en pervertidas traducciones españolas. Ocurre a veces que un mismo estereotipo tenga una doble filiación, como, por ejemplo, los que saturan a la par el texto tanguero y la narrativa rusa: el texto argentino los amalgama en un proceso continuo de digestión.

Son reconocibles estos esquemas, entre otros criterios, por dos indicios: la ampulosidad y la cursilería, por una parte (patentes en particular en la adjetivación: lindo, genial..., fragante aroma, extraordinaria alegría...) y, por otra, la redundancia. Por estos rasgos se delata el discurso huero que se mira a sí mismo en un ejercicio mimético.

\subsection{Intertexto folletinesco}

Varios críticos han hecho hincapié en la fuerte presencia del registro folletinesco en los textos de R.A. ${ }^{5}$. La especificidad de este primer texto novelesco es que asume la incorporación de este subgénero literario tanto en el ámbito diegético como en el de la escritura. Es significativo que en esta "novela de formación" el texto se abra con el aprendizaje literario del héroe al contacto de las descabelladas aventuras de bandoleros españoles ("Dicha literatura, que yo devoraba en las "entregas" numerosas, era la historia de José María, el Rayo de Andalucía, o las aventuras de Don Jaime el Barbudo...", I, 8), y que en

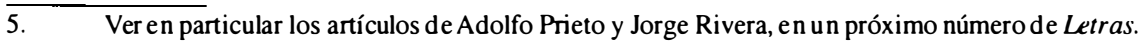


las últimas páginas, antes de cometer el crimen de traición, el personaje recuerde "con nitidez asombrosa" un fragmento de las aventuras de su héroe predilecto, el sin par Rocambole (IV, 126). Silvio se jacta, ante sus compañeros del club anarquista, de haberse leído los 40 tomos de la obra de Ponson du Terrail (I, 10). A lo largo de la narración se mencionan otros melodramas y folletines: uno argentino, Las aventuras de Musolino (II, 44), otro español, "el truculento novelón" del prolífico valenciano Luis de Val, Virgen y Madre (III, 71), así como "las novelas de Carolina Invernizio", popular folletinista italiana (IV, 101), producciones todas ellas de la segunda mitad del siglo XIX y de la primera década del siguiente.

2.1.1. Los estereotipos comunes en las "novelas por entregas" son retomados por la escritura arltiana, por ejemplo cuando Silvio sueña con "una Alhambra inefable": "veía los cármenes de la Andalucía distante [...] y en lo hondo de los socavones la cinta de plata de los arroyuelos" (IV, 107).

\subsubsection{Las aventuras de Rocambole}

Se rastrean varias huellas "rocambolescas" en los procedimientos narrativos y escriturales: "bricolaje" a partir de textos anteriores, uso y abuso de la frase admirativa, de los puntos suspensivos, redundancias y anáforas. En la cita de La resurrección de Rocambole ya mencionada, a través de la evocación del "torbellino embriagador" del París del siglo XIX, "aquel mundo de luz y de ruido" (IV, 126), se reconoce la Buenos Aires de la calle Lavalle, que el texto arltiano presenta "en su más babilónico esplendor" (II, 61).

\subsubsection{Los lugares comunes de la cursilería}

El ambiente romanticón de los amores juveniles del personaje es también de traza folletinesca: "Tenía un vestido rosa té, y me acuerdo que muchos pájaros cantaban en lo verde" (I, 31). 
En la adjetivación, los diminutivos y la reiteración se delata por todas partes la impronta de la infraliteratura folletinesca. Todas las variantes de la lexía "la vida es linda" se repiten en un fragmento tcxtual del capítulo II, alternando con otro estilema: "linda noche". El texto presenta nada menos que treinta ocurrencias de lindo:

Doña María miró el cielo constelado.

-Linda noche... [...]

—Sí, es linda la noche (II, 68).

A continuación - como ocurre a lo largo de todo el texto- el personaje mantiene un diálogo con su otro yo, del cual doy unos extractos:

-Ésta es la hora de las muchachitas... y de los poetas... [...]

—Vida, Vida, qué linda sos, Vida... Y sin embargo, yo amo todas las cosas más hermosas de la tierra... [...] Vida, quélinda que sos. Vida... qué linda... Dios mío, qué linda que sos (ibíd.).

En el capítulo IV se repite de nuevo el leitmotiv (IV, 120).

\subsection{Narrativa rusa mediatizada por el folletín}

R.A. fue un gran lector y admirador de los rusos. De esta afición dejó varios testimonios en sus crónicas periodísticas, las famosas Aguafuertes porteñas. Como sus contemporáneos, leyó a Tolstoi, pero sobre todo a Dostoievski y a Andreiev, en las distorsionadas y cndulzadas traducciones de la Editorial Tor, que circulaban por toda América Latina. Las huellas del intertexto ruso son numerosas en la obra de R.A., hasta tal punto que Onetti sintetizó dicha singularidad con estas palabras: "Roberto Arlt tradujo a Dostoievski al lunfardo"6.

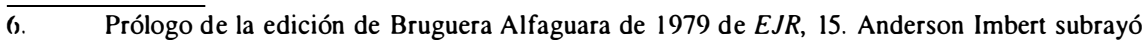
irónicamente la identificación que hicieron varios críticos de R.A. con este escritor ruso: "Se le consideró [...] como a un pequeño Dostoievski" (Historia de la literatura hispanoamerica$n a, \mathrm{t}$. II, citado por T. Muñoz Molina, en su introducción a la última edición de $E J R$ de la Editorial Espacio, 33). 
La mayoría de los clichés y tópicos procedentes de la literatura rusa de tal modo infraliterarizada, y que el texto de $E J R$ reescribe, remiten a las grandes problemáticas humanas y metafísicas: el sacrificio expiatorio, las tinieblas del alma, la búsqueda de Dios en la abyección, el crimen. Muchos estereotipos de la literatura policíaca circulan por ambos textos. El héroe Silvio, de personalidad escindida, que busca su verdad profunda por la senda del mal, en un dialogismo permanente con la gran ciudad que lo excluye y lo protege al mismo tiempo, presenta muchas afinidades con los personajes de los novelistas rusos.

El caso del intertexto de Andreiev es particularmente interesante. El personaje de la madre de Silvio es una deconstrucción de la figura arquetípica de la madre rusa que sacrifica su vida por el hijo, y que el propio Arlt exaltó en una de sus Aguafuertes porteñas, «La madre en la vida y en la novela». El texto retoma la figura materna de $L o s$ siete ahorcados, esa "carnecansada y dolorosa"7 , en la imagen de la madre heroica que se le aparece a Silvio en uno de sus numerosos sueños:

[...] Caminaba a la orilla de los caminos [...] estrechando todo mi cuerpecito contra su cuerpo mezquino [...] y de su boca hambrienta se quitaba el pan para mi boca (II, 43).

Tras su tentativa de suicidio, lo vela su madre. De nuevo surge el tópico recurrente de la madre abnegada, que sufre en silencio por el hijo descarriado, y la imagen del rostro de mater dolorosa: "Tenía mojadas las pestañas, y su rostro de rechupadas mejillas parecía excavado en un arrugado mármol de tormento" (III, 98).

\subsection{La cultura-tango en $E J R^{8}$}

Debido a la fuerte presencia del tango en la cultura argentina de las primeras décadas del siglo $\mathrm{XX}$, los imaginarios y las retóricas que

7. $\quad$ En O.C. (t. 2), 489-491.

8. Las citas de tangos están sacadas de los ensayos de Rébora y Salas, así como de Idea Vilariño, selección, prólogo y notas. Tangos: Antología (Buenos Aires: CEDAL, 1981). Todos ellos, que 
le son específicos se insinúan ineludiblemente en todos los géneros de la literatura rioplatense, tanto en los pertenecientes a la cultura periférica, como en los de la jerárquica. Baste con citar los nombres de Borges, Sábato, Cortázar, Puig, Marichal y otros más, cada uno de los cuales, a su modo, reconoció su deuda respecto del tango.

A partir del momento en que surge, en 1917, el tango-canción con «Mi noche triste» de Pascual Contursi, cantado nada menos que por Gardel, este producto cultural se va constituyendo en mito urbano contemporáneo, en testimonio de las hibridaciones generadas por la inmigración masiva, de los sueños, las miserias y las traiciones de la mayoritaria clase media argentina.

Los textos arltianos tampoco escapan a su penetración: en $E J R$ se deconstruyen y redistribuyen varias de las figuras emblemáticas y de los trasnochados tópicos del melodrama tanguero.

2.3.1. La dicotomía espacial: el arrabal de la nostalgia y la ciudad de la perdición

La fractura psíquica de "medio pelo" argentino con el que se identifica el narrador del tango-canción reproduce otra división, la de la ciudad que le es indisociable: la babilónica Buenos Aires. La misma organización, a la vez referencial y simbólica, estructura el discurso sobre el espacio en la novela de R.A.

* La zona híbrida arrabalera es el lugar donde se congregan los únicos valores positivos del universo creado por el tango: el amor a la madre (que ocupa todo el espacio familiar, del que está evacuado el padre), el trabajo honrado y la vida sencilla. Es el paraíso de la niñez y de los primeros amores, que siempre se expresa mediante el lenguaje conservador del pasado.

En «Melodía de arrabal» del letrista de Carlos Gardel, Alfredo Le Pera, o «Viejo rincón» de Roberto Cayol, se aglutinan los tópicos

inevitablemente pertenecen al repertorio gardeliano, son anteriores a la crisis de 1930. La mayoría debían de ser conocidos en el período de la escritura de $E J R$ (1919-1925). 
de la evocación nostálgica del barrio, casi siempre relacionado con la figura adorada de la novia:

\author{
Rinconcito arrabalero \\ con el toldo de estrellas, \\ de tu patio que quiero; \\ todo, todo se ilumina \\ cuando ella vuelve a verte («Arrabal amargo», Le Pera)
}

El primer capítulo de las "memorias" de Sil vio Astier transcurre en la parroquia de Flores, barrio antiguo de las clases modestas, donde en las primeras décadas todavía persistían huellas de ruralidad: es para el personaje el tiempo de la niñez despreocupada y las esperanzas, el de los juegos e inventos, el de los amores idealizados: " $¡$ Te he querido, Eleonora! ¡Ah!, ¡si supieras cuánto te he querido!" (I, 35).

* El centro urbano es el espacio de las tentaciones y de la perdición del hombre, donde se hacen intolerables las desigualdades sociales: allí, los pobres diablos, los buscavidas, desde abajo, contemplan el lujo ostentoso de los "bacanes" (hombres ricos que mantienen a una querida) y de las "cocottes" de lujo.

Silvio arrastra su rencor y su humillación por las calles de "babilónico esplendor" y por los opulentos barrios residenciales de Buenos Aires adonde le conduce su trabajo:

Pensaba en las fiestas a que ellos asistieron, las fiestas de la ciudad, las fiestas en los parajes arbolados con antorchas de sol en los jardines florecidos [...] (II, 63).

\title{
2.3.2. La pareja funcional: madre e hijo
}

* El narrador, tanto de la novela como del tango, es un hombre triste, abandonado, "un viajero del dolor". Los títulos-clichés de muchos tangos son evocadores: «Aquel muchacho triste» de José 
de Grandis, «Mi dolor» de Meaños, «Pobre corazón mío» de Pascual Contursi, entre otros. Se repite de tango en tango el mismo estilema "triste y solo":
[...] pero, ingrata, te fuiste, y en mi mal triste y solo, cobarde, te lloré («Nunca más», Óscar Lomuto)

El personaje de R.A. hace igualmente del dolor su emblema y, como el protagonista del tango, llora su desamparo y sus frustraciones sexuales, usando el mismo lenguaje del melodrama sentimental, cursi y redundante. El fragmento textual siguiente se sitúa después de haber recibido Silvio "un beso de propina" de la "cocotte" de lujo francesa a quien su patrón le mandó entregar unos libros:

[...] sé que si me encontrara otra vez junto a ella desfallecería de amor; pienso que no me importaría pensar que ha sido poseída por muchos hombres y que si me encontrara otra vez junto a ella en esa misma sala azul, yo me arrodillaría en la alfombra y pondría la cabeza sobre su regazo [...] (II, 65).

En la expresión del sufrimiento, Silvio utiliza los mismos clichés que el tango. He aquí un ejemplo: "mis ojos se secaron para el llanto" (II, 67). En estas palabras se oye como un eco de los versos de «Sus ojos se cerraron» de Le Pera:

Y ahora que la evoco

hundido en mi quebranto

las lágrimas trenzadas

se niegan a brotar...

* La madre santa. Trabajadora y sufrida, sólo ella puede amparar al hijo humillado, que siempre vuelve un día a ese último 
refugio. Instalada en el vacío dejado por la ausencia paternal, la pareja madre-hijo del tango está evidentemente marcada por un fuerte edipo. La madre salva al hijo indefenso del contagio del mal encarnado por la mujer sexual — la milonguera-. De este discurso maniqueísta y misógino, que adopta esquemas morales reaccionarios que remiten a la tradición de los Padres de la Iglesia, se deriva una larga serie de clichés y tópicos del tango. Son innumerables los títulos tópicos que se refieren a ese asunto: «Pobre mi madre querida», «Madre hay una sola» de E. Cadícamo o simplemente «Madre» de Servetto y Pracánico, grabado por Gardel en 1922. Estos versos de «La casita de mis viejos» de Celedonio Flores pueden resumirla:

\section{[...] sólo una madre nos perdona en esta vida, es la única verdad, es mentira lo demás.}

El discurso magnificador de la figura materna entra en el texto arltiano metabolizado con el texto ruso mencionado más arriba. Cada vez que en el relato aparece la madre de Silvio, se la ve agobiada y resignada a padecer en silencio. Esta imagen persigue al protagonista, torturándole y culpabilizándole. Tras su tentativa fallida de suicidio, la encuentra al despertar a su cabecera: "por la ojera carminosa le descendía una lágrima pesada" (III, 98).

La propensión lacrimógena es uno de los componentes específicos del universo del tango, verdadero valle de lágrimas. Se podría citar una copiosa cantidad de ejemplos de este llanto inacabable, como este, que parece dialogar con el fragmento precedente:
[...] cuántas veces, embozada, una lágrima asomada, yo no pude contener («Cuesta abajo», Le Pera). 
La sensiblería tanguera contamina el texto de R.A., sobre todo en los capítulos centrales, II y III, donde se amalgama con el intertexto ruso y el bíblico. El punto central donde convergen estas tres representaciones del dolor humano - la melodramática del tango, la metafísica de la narrativa rusa y la religiosa de la Biblia - podría denominarse texto de las lamentaciones. La sistemática de esta estructuración la convierte en uno de los elementos morfogenéticos más activos de la producción de sentido en el texto.

\subsubsection{Hembras, compadritos y bacanes}

En los textos de los tangos circulan, además de la pareja madre/ hijo, otras figuras estereotipadas que también forman parte de la mitología porteña.

* Lanovia es el tercer elemento positivo de la trilogía que remite al paraíso de la juventud arrabalera. Suele aparecer la "muchachita en flor" en la plenitud de su hermosura juvenil, "linda como una flor". Esta presencia en el texto de la amada ausente se expresa mediante tópicos, que han hecho el éxito de muchos tangos-canciones como el histórico «Mi noche triste» de Contursi:

\section{Y el espejo está empañado \\ y parece que ha llorado \\ por la ausencia de tu amor.}

En $E J R$, la novia de "rostro sereno y dulce" surge reiteradamente en las visiones oníricas de Silvio, según un esquema narrativo análogo, pero con una carga de misterio y un "aura" de que carece el texto tanguero:

"[Dulcemente, como una sombra en un muro blanqueado por la luna, pasó toda ella] y en cierto anochecimiento lejano [vi] el 
semblante de imploración de la amada niña [...]" (I, 35 y III, 80 y 90$)^{9}$.

Los demás tipos humanos del tango están marcados por el signo negativo debido a su connotación sexual.

* Milongueras, francecitas y mantenidas/bacanes, compadritos y cafishios obsesionan las noches del protagonista. La milonguera es aquella «Flor de fango» (Contursi), que abandonó el barrio de las estrecheces por las tentaciones de la ciudad depravada, "flor de noche y de placer/ flor de lujo y cabaret" («Milonguita» de Linning). Algunas adoptan los nombres prestigiosos de las francecitas, Margot, Ivette o "la rubia Mireya"..., que remiten a una realidad de la Argentina de las primeras décadas del siglo XX, la "trata de blancas", origen de un fructuoso comercio prostibulario en torno al cual se mobilizan los llamados cafishios (palabra lunfarda que designa a los proxenetas), procedentes muchos de ellos de Marsella. De esta realidad, el gran periodista Albert Londres dejó un importante testimonio ${ }^{10}$.

De estas representaciones de la sexualidad tentadora o frustrada hallamos muchas huellas en el texto arltiano. El exaltado adolescente Silvio sueña con las "cocottes" francesas (la palabra está repetida varias veces en el texto), y elabora planes con su amigo, el medio cafishio Rengo, para vivir en París como unos bacanes, manteniendo a una querida en una «Garçonnière» (título de un tango de Caruso y Canaro). La ideología pequeño burguesa invade el discurso tópico del personaje y de su compañero:

- Las hembras nos seguirían; nosotros cruzaríamos como grandes bacanes las ciudades al otro lado del mar.

-Dicen que allí los que saben bailar el tango se casan con millonarias (IV, 120-121).

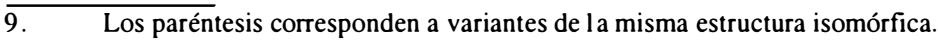

10. «Le chemin de Buenos Aires (La traite des Blanches)» (1927, Oeuvres Complètes, París: Arléa-Seuil, 1992) 358-445. 
Atormentado de deseos, Silvio sueña con ese "beso de propina" de la coqueta mantenida francesa, fabricada sobre el mismo modelo estereotipado que aquellas "Deliciosas criaturas perfumadas" del fox trot de Le Pera «Rubias de Nueva York», texto que servirá, varias décadas después, de embrague narrativo a la novela de Manuel Puig, Boquitas pintadas. La maravillosa cortesana de "liviana melenita y amplio escote" (II, 64-65) lo recibió a él, miserable empleadito "archipobre", en su opulento apartamento.

El compadrito porteño, hombre del suburbio, provocador y pendenciero, con ribetes de rufián, es también inseparable del tango, cuyo narrador a menudo lo caricaturiza ("vestido como un dandy, / peinado a la gomina...", en «Bailarín compadrito» de Bucino). En el texto de R.A., esta figura masculina está deconstruida y redistribuida entre dos personajes, Lucio, el antiguo ladrón "regenerado", que también se pavonea como un dandy, y el pícaro Rengo, el compadrito del lumpen, macró del proletario barrio de Caballito (IV).

Elintertexto tanguero también aflora en el ámbito lingüísticoen los numerosos sintagmas fijos, así como en las imágenes estereotipadas, que funcionan como leitmotivs, reactivando incesantemente la escritura.

\subsubsection{Los estereotipos lexemáticos}

Entre las expresiones que configuran el texto semiótico vida/ muerte en $E J R$, se destaca una en particular por su significativa recurrencia: "así es la vida". Este esquema desgastado sintetiza la "filosofía" popular del desencanto y de la resignación, que impregna la letra de los tangos. Lo encontramos en el estribillo de «Paciencia» de F. Gorrindo: "Paciencia.../ La vida es así..."; en la variante de "Volvió una noche» de Le Pera: "es la vida". El tópico se trivializa conE.S. Discépolo, en su conocido «iQué va- cha- ché!» (¿Qué vas a hacer!).

La expresión lexicalizada aparece en el $E J R$, en un fragmento de traza romanticona, cuando evoca Silvio con nostalgia y llanto la ruptura con su novia. "Así es la vida", comenta su amigo Enrique con 
fatalismo (I, 31). Se repite así mismo dos veces en la confrontación dolorosa del hijo sin trabajo con la madre abrumada por la dureza de la vida (II, 43). El motivo obsesivo asoma de nuevo en el discurso conformista de Lucio, el antiguo anarquista "regenerado", como moraleja de la última aventura de Enrique, el tercer ladrón del grupo, que acaban de encarcelar (IV, 105).

Este motivo repetitivo transcribe un momento de la historia argentina, cuando una parte de la insegura clase media, pauperizada, desengañada, se aliena, adhiriéndose a las opciones derechistas que desembocarán en el golpe militar del General Uriburu, que en 1930 derrocará al presidente radical Yrigoyen, portavoz de la clase media, y cuyas consecuencias serán catastróficas para el país ${ }^{11}$.

\subsubsection{Las imágenes-clichés}

En el ámbito de los imaginarios, el texto recupera el material trasnochado que se sedimenta en la letra de los tangos. Elijo una de esas imágenes, cotejando dos segmentos textuales. El tango-canción de Celedonio Flores acusa al hijo sin entrañas:

Se murió tu pobre madre, y en el mármol de tu frente ni una sombra ni una arruga.

El texto de R.A., retomando el tópico del rostro impasible, lo adapta a una situación totalmente distinta: la madre desesperada por la locura suicidaria del hijo: "Su rostro de rechupadas mejillas parecía excavado en un arrugado mármol de tormento" (III, 98).

11. A lo largo de la llamada "Década infame" se van reforzando las bases ideológicas del sistema militar que, tras el paréntesis justicialista, va a perdurar en Argentina hasta una fecha reciente. 


\subsection{Primeras conclusiones: intertextualidad y sociedad}

El conjunto que hace aflorar el rastreo de la intertextualidad en $E J R$ (folletín, literatura rusa infraliterarizada, melodrama tanguero), construido en torno a las nociones de nostalgia, humillación, frustración y dolor ${ }^{12}$, de obsesiva circulación en el texto, tiene su origen extratextual en la formación sociodiscursiva contemporánea de la escritura. En esta sociedad argentina no es casual que nazca y se desarrolle como mito identificador de la argentinidad esa cultura-tango, que resulta ser una de las expresiones más cabales de las ilusiones y frustraciones del estrato social medio. La década de los veinte es precisamente aquella en que las masas argentinas (los excluidos de la prosperidad por el lobby agropecuario y la presión del capitalismo inglés, la pequeña burguesía procedente mayoritariamente de la emigración europea), tras el fracaso de los modelos socioeconómicos de desarrollo, están refluyendo hacia un pesimismo y una ruptura del compromiso político — antes canalizado por el radicalismo-y que la ideología conservadora va a saber explotar. En el campo cultural, tanto las novelas de R.A., como los tangos "metafísicos" de E. Santos Discépolo y el grotesco paródico de los sainetes de Armando Discépolo, son transcriptores de aquella mutación sociológica y de los signos precursores de la catástrofe que se avecina. Observamos así cómo la estructuración que llamamos texto de las lamentaciones, que se sistematiza en $E J R$ y convoca las representaciones de la paraliteratura,

12. David Viñas propone una lectura operativa de los textos "quejumbrosos" del escritor. De su discurso crítico elaborado a partir de los conceptos centrales de humillación y seducción, extraigo un fragmento: "Lo inmediato que se lee ahí son ruegos, rogar, pedir a los demás. [...] Entonces, trato de ver de más cerca: ruegos y quejas y los protagonistas de eso que pueden llamarse Astier o Erdosain; más atrás hay otros que corean esa entonación [...] pero como Arlt se maneja con la historia y no con "caracteres" no puedo conformarme diciendo que si se oyen que jas es porque se trata de un quejoso. [...] Y yo necesito seguir adelante: un quejoso es una resultante [...]. Entonces hago girar los ruegos y las que jas como si fueran paneles movibles de un teatro y leo: carencias. Ahora estoy en el centro del universo arltiano" (David Viñas, «El escritor vacilante: Arlt, Boedo y Discépolo», Literatura y realidad política. De Sarmiento a Cortázar (Buenos Aires: Siglo Veinte, 1974) 64. 
se articula con las prácticas sociales y discursivas textuales y extratextuales analizadas en esta parte del estudio y que tan masivamente están representadas en la Argentina de los años 20.

En última instancia, el dialogismo interdiscursivo que se instaura entre el tango y la novela es el producto de una Historia común, cuyos actores son los grupos sociales que constituyen la vacilante y desclasada pequeña burguesía argentina. En cuanto a la idealización del barrio-refugio, de las madres santas y de las hermanitas y novias honestas, transcribe una fuerte reivindicación del hogar proletario contra la dependencia económica que pauperiza a las masas y contra la inmoralidad de la clase dirigente.

\section{La renovación de los estereotipos}

3.1. Función subversiva y regeneradora de los clichés en $E J R$

Ahora bien, se trata de comprender cómo funciona ese material paraliterario que se acaba de definir y que se ha localizado en las representaciones culturales que se deconstruyen en el texto arltiano. La subcultura popular origina dos reacciones desde la zona privilegiada: ya sea la expulsión y la marginación por la elite en nombre de valores consagrados y del "buen gusto", o bien la observación como objeto de reflexión, que puede ir hasta la incorporación experimental de los clichés en los textos de la cultura de referencia. La imitación paródica en la novela tiene una larga tradición literaria, que entronca con El Quijote y perdura hasta hoy día.

La novedad del texto de R.A., dentro del ámbito cultural argentino, es que no se limita al pastiche paródico, sino que realiza en sus profundidades un trabajo creativo de reelaboración del material desgastado, de importantes implicaciones estéticas e ideológicas. Los tópicos y estereotipos entran en el sistema semiótico textual según unas modalidades variadas y con una nueva funcionalidad.

Para explorar esa actividad propulsada por el genotexto, el análisis ha de captar, en las manifestaciones fenotextuales producidas 
a raíz de la penetración del material desclasado, todos los deslizamientos y las distorsiones que asomen por el texto. La escritura moviliza varias técnicas para realizar esta labor de regeneración de los estereotipos.

\subsubsection{La adaptación mimética}

En este "grado cero de la reescritura" del material infraliterario, el texto transcribe las estrecheces, los sueños y las ilusiones de la clase media argentina, que se encarnan en Silvio Astier. El narrador se identifica, en varios momentos del relato, con el discurso ampuloso y desfasado de la pequeña burguesía, que suele mezclar eslóganes conformistas, expresiones trasnochadas y emplea el lenguaje de la cursilería. Esa función mimética se inscribe en la coherencia de un textoque asume su heterogeneidad como principio de su composición.

El cliché opera también, en este caso de mimetismo, como disparador de la imaginación del personaje. Así es como el "beso de propina" que le regala la "demi-mondaine" va a repercutir en las imágenes eróticas que de noche se proyecta a sí mismo en el muro de la "caverna de los libros" donde vive y trabaja.

Sin embargo, a partir del momento en que este registro melodramático entra en contacto con otros niveles literarios, los unos igualmente populares (el género policíaco lunfardizado, por ejemplo), los otros elevados (escritura novelística de referencia, discurso científico de fuerte representación en el texto, etc.), se ponen de manifiesto las diferencias que inferiorizan al primero. Los fragmentos de la "otra" cultura sufren inmediatamente en el texto que los acoge unos ataques frontales u oblicuos que los desestabilizan, los deconstruyen y los subvierten, ya sea con fines paródicos, o bien para revitalizarlos.

\subsubsection{Parodia y subversión}

Se produce, por tanto, una difracción del punto de vista, que introduce el distanciamiento paródico. 


\subsubsection{1. "La orgía de redundancias"13}

La repetición a ultranza, procedimiento técnico característico de esta literatura novelesca popular, produce a menudo un efecto grotesco que es patente en el monólogo ya mencionado, donde se reitera tediosamente el cliché "la vida es linda" en todas sus variantes.

\subsubsection{La confrontación de discursos heterogéneos}

3.1.2.2.1. Introducción en el discurso infraliterario de un elemento alógeno

Mediante esta técnica, la escritura subvierte radicalmente el estereotipo en un sentido grotesco. En un largo pasaje del "relato segundo" (constituido por los monólogos, los paréntesis alucinados del narrador personaje), se narra uno de los numerosos sueños eróticos de Silvio, donde son evocados los "rostros de doncellas que hieren con espadas de dulzura" (el oxímoron es de uso frecuente en la lengua tópica). De repente, en medio de esta representación, irrumpe una palabra inesperada que va a neutralizar la emoción del momento:

Rostros... rostros de doncellas maduras para las desesperaciones del júbilo,... rostros que... acrecientan en las entrañas un desfallecimiento ardiente [...] (II, 52-53)

He aquí otro ejemplo del efecto paródico producido a raíz del choque de palabras procedentes de niveles dispares: "Quisiera ser lindo y genial... [...] y ser taciturno..." (II, 68).

Este adjetivo taciturno remite a los versos de Las flores del mal de Baudelaire citados en el primer capítulo de la novela.

13. Empleo la expresión de Umberto Eco ensu ensayo sobre los héroes de los folletines populares, De Superman au Surhomme (París: Grasset, 1993). 
3.1.2.2.2. Colisión de dos enunciados próximos semánticamente, pero de distinta procedencia cultural

Es el caso del tópico de la aceptación fatalista "así es la vida". Aparece en un fragmento textual heterogéneo donde se mezclan la lengua paraliteraria y el lenguaje lunfardizado del delito, con el discurso ciéntifico. El cliché se halla revitalizado por su cotejo con otro leitmotiv, la expresión darwiniana, "struggle for life" repetida cuatro veces y subrayada por la bastardilla en el texto original:

- ¡La struggle for life, che..., unos se regeneran, otros caen! ...¡Así es la vida! (IV, 105).

Aunque ambos sintagmas no coincidan exactamente (la cita inglesa introduce el sema del combate), esta confrontación interdiscursiva dinamiza el conjunto semiótico, dando nueva fuerza expresiva al cliché desgastado.

3.1.2.2.3. El choque del tópico con una creación verbal arltiana

Un conjunto ampuloso puede ser subvertido por la incorporación de un elemento lingüístico que brilla por su novedad. Es el caso de la siguiente evocación tópica de los puertos del placer y de las fiestas de las cuales son excluidos los pobres:

[...] mis ojos creían ver [...] navíos de mástiles florecidos deslizándose entre armonías de sirenas hacia las fúricas ciudades de la alegría (IV, 106).

[...] afuera estaba el cielo de la mañana, quieto y exquisito, dejando caer de su azulidad la infinita dulzura de la primavera (ibíd.). 


\subsection{El dialogismo interdiscursivo}

El diálogo que se instaura entre discursos heterogéneos obedece a dos funciones:

\subsubsection{La función lúdica}

La escritura instaura un juego combinatorio, dejando los diferentes elementos colisionarse libremente entre ellos, derivándose de este funcionamiento textual unos efectos sorprendentes. De este modo saca de un material anquilosado una nueva belleza subversiva, un neodiscurso de fuerte impacto, como se ha podido observar en los últimos ejemplos citados.

\subsubsection{La función liberadora}

La adición de un elemento heterogéneo procedente de otro sistema literario tiene por efecto subvertir la función conservadora y alienante que desempeñan los estereotipos en los productos del macrosistema literario. Lo averiguamos, por ejemplo, en un diálogo entre los dos yo de la personalidad escindida de Silvio, en el que el texto retoma el tópico del discurso teológico de la ineludibilidad y sanctificación del sufrimiento humano, tan explotado por la ideología reaccionaria, y subvierte los efectos alienantes de la aceptación resignada. Se logra esa neutralización mediante el encuadramiento del fragmento por dos frases de un discurso ajeno con las que se abre y se clausura aquel:

Entonces repetí palabras que antes habían tenido un sentido pálido en mi experiencia.

—Sufrirás —me decía-, sufrirás...sufrirás...sufrirás...

- Sufrirás... sufrirás...

—Sufrirás... "y la palabra se me caía de los labios" (II, 67). 
En todo el texto de $E J R$ se generaliza la confrontación interdiscursiva provocando unas tensiones e instaurando una dialéctica de la seducción y el rechazo entre el arqueodiscurso y el neodiscurso.

\section{Una nueva poética: el modelo baudelairiano}

El texto de R.A. se refiere reiteradamente a Baudelaire, cuyo nombre aparece cuatro veces y que es, con Rocambole, uno de los modelos de referencia del héroe ("un poeta genial como Baudelaire"; II, 48) ${ }^{14}$. La cita de cuatro versos de Las flores del mal en el primer capítulo, el de su iniciación literaria, es emblemática de la fuerte impronta del poeta francés en todo el texto. Es interesante constatar la analogía del proceso de renovación de los tópicos románticos que se realiza en el texto famoso de Baudelaire (el flechazo de amor, el exilio del Poeta en esta tierra, etc.), con el que acabamos de describir en el argentino. El poeta se sirve como estructura dinámica del choque de los contrarios (los textos semióticos como el mundo de abajo / el de arriba, lo material / lo espiritual intervienen constantemente en el trabajo de producción del sentido, de la misma manera que lo hacen en el texto de R.A.). En su poesía opera la dualidad conflictiva, del mismo modo que en la letra de los tangos o en las novelas rosas funcionan el texto semiótico del Bien y del Mal, así como las inversiones de situaciones (por ejemplo: la mujer pecadora que se purifica cumpliendo un gesto de sacrificio, entre otras).

En los primeros poemas de «Spleen et idéal» se concentran un gran número de clichés. El poeta maltratado, exiliado en este mundo de miseria, acepta gozoso sus sufrimientos, en vista de la redención de la humanidad:

14. En uno de sus primeros textos, Las ciencias ocultas en la ciudad de Buenos Aires (1920), cuenta el narrador de esta autobiografía que "la influencia literaria de Baudelaire y Verlaine" motivó su aventura esotérica. "Principalmente Baudelaire, las poesías y bibliografía [sic] de aquel gran doloroso poeta me habían alucinado al punto que [...] era mi padre espiritual, mi socrático demonio, que recitaba continuamente en mis oídos, las desoladoras estrofas de Las flores del mal" (O.C., 531). 
Soyez béni, mon Dieu, qui donnez la souffrance

Comme un divin remède à nos impuretés («Bénédiction») ${ }^{15}$.

En «A une passante», se revitaliza el trasnochado tópico del repentino flechazo del amor por una desconocida:

Un éclair... puis la nuit! — Fugitive beauté

Dont le regard m'a fait soudainement renaître,

$\mathrm{Ne}$ te verrai — je plus que dans l'éternité? ${ }^{16}$

\subsection{La subversión del modelo consagrado}

Un juego intertextual se instaura en $E J R$, que cita, distorsionándolo, estos versos del Poema XXIV de las $F M$, construido a partir de varios estereotipos de la literatura amorosa (las versiones originales figuran entre corchetes).

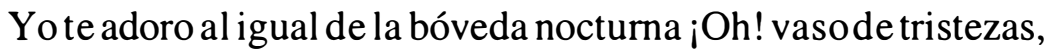
$¡$ ¡h! blanca [grande] taciturna. [...] y vamos a los asaltos, vamos, como frente a un cadáver, un coro de gitanos [gusanos] (I, 32).

La segunda manipulación, por contaminación paronomástica, del texto poético (gusanos/gitanos) operada por la escritura arltiana pulveriza el tópico de la putrefacción del cadáver.

\subsection{Arlt, Baudelaire y el tango}

Del análisis que precede se pueden sacar unas primeras conclusiones sobre el complejo sistema intertextual tal como funciona en

\footnotetext{
15. "Bendito seas, Dios mío, que das el sufrimiento / cual divino remedio de nuestra impureza" (FM, en Oeuvres Complètes, 6).

16. "¡Un relámpago... luego la noche! - Fugitiva bcllcza / cuya mirada de repente me hizo renacer, / ¿ya sólo te veré en la cternidad?" («A una mujer que pasó», 69).
} 
$E J R$. El texto presenta a un Baudelaire mediatizado por el tango, al reelaborar los tópicos de la cultura de referencia mezclándolos con los clichés que saturan la letra del tango, en un trabajo de renovación de la escritura literaria que coincide con el que llevó a cabo el poeta. Parafraseando la frase ya citada de Onetti ("Roberto Arlt tradujo a Dostoievski al lunfardo"), se podría también decir que "el tango tradujo a Baudelaire al lunfardo". En efecto, Alfonso Reyes señaló ${ }^{17}$ las correspondencias intertextuales entre el esquema "Araca ${ }^{18}$, corazón, cállate un poco" del tango de A. Vacarezza, y el primer verso de «Recueillement»: "Sois sage, ô ma douleur, et tiens-toi plus tranquille"19. Aquí se da el fenómeno inverso de la recuperación por el discurso infraliterario de un texto de la cultura de prestigio.

El gesto rupturista de R.A., incorporando por vez primera en el género noble de la novela el material desgastado de la subcultura popular, remite al de Baudelaire. Su uso provocador de los lugares comunes de la cursilería suena como un eco de estas palabras del poeta: "Ce qu'il y a d'enivrant dans le mauvais goût, c'est le plaisir aristocratique de déplaire" 20 .

La crítica argentina reaccionó ante la subversiva novela de R.A. igual que lo hiciera en su tiempo la francesa respecto del libro del poeta maldito, con la misma incomprensión inicial y la misma adhesión entusiasta de la posteridad. Ambos textos inauguraban una nueva poética de la modernidad en sus épocas respectivas, haciéndola emerger de las ruinas del pasado.

\section{Fenotexto y genotexto: la creación de nuevos estereotipos}

El análisis sociocrítico de las manifestaciones fenotextuales relacionadas con la penetración de los enunciados y los imaginarios de

17. Alfonso Reyes, La experiencia literaria (1952) (Buenos Aires: Losada, 1969) 145-146.

18. Término lunfardo: ¡cuidado!

19. Op. cit., 127. Rosalba Campra recoge el dato en «Relaciones intertextuales en el sistema culto/ popular. Poesía y tango», Hispamérica, XVII (1988) 19-32.

20. "Lo embriagador en el mal gusto está en el placer aristocrático de disgustar" (Fusées XII, en Journaux intimes, O.C., 396). 
la paraliteratura permite explorar, por debajo de la superficie del texto, la zona de programación donde se realiza la actividad genotextual. Se constata, en efecto, que el texto del $E J R$ secreta nuevos clichés que entran en competencia con el material estereotipado intertextual.

Finalmente, el texto arltiano logró realizar, en el ámbito de la narrativa, la empresa que Baudelaire no tuvo tiempo de llevar a cabo en la poesía. En sus Journaux intimes exclamaba este exaltado: "Créer un poncif, c'est le génie. Je doit créer un poncif"21.

El texto de R.A. produce unos esquemas expresivos e imaginativos, que, al entrar en el sistema de repetición mimética que funciona operativamente en él, adquieren a su vez el estatuto de nuevos clichés autoplagiables. Así se crea un sistema autorreferencial que introduce una circularidad análoga a la que opera en el universo tanguero ${ }^{22}$.

\subsection{Creación de formas miméticas}

Voy a dar unos ejemplos de estructuras que se repiten con algunas variaciones lexicales y unas modificaciones del orden sintáctico, que son las que precisamente introducen la libertad dentro de un registro anquilosado.

Primer ejemplo: la arruga

*...una arruga dilatada le hiende la frente desde la raíz de los cabellos al ceño (I, 38).

Aquí el rasgo se atribuye a Enrique.

*Un surco oscuro le hendía la frente desde el ceño hasta la raíz de los cabellos... (II, 42).

21. En Fusées XIII, op. cit., 397. "Crear u n cliché, eso es ser genial./ He de crear u n cliché".

22. "El tango-canción fue a menudo autorref erencial: habló de sí mismo con abundancia y versatibilidad, no se privó de hacer su propia apología, pero tampoco fue reacio a la autocrítica [...]", R. Campra, 26. 
Ahora se trata de la madre envejecida de Silvio.

Segundo ejemplo: el perfil adolescente

El mismoEnrique, el Falsificador, el único del grupo que seguirá fiel al ideal libertario de la adolescencia, se halla aquí fijado en la siguiente postura:

*En el muro de la covacha de los títeres, el rayo rojo iluminaba el demacrado perfil del adolescente (I, 40).

En el último capítulo, la evocación por Lucio de la dramática prisión del amigo rebelde, convoca inmediatamente la misma imagen:

*Recordaba a Enrique [...]. En el muro rojo el rayo de sol iluminaba su demacrado perfil de adolescente [...] (IV, 105).

Tercer ejemplo: el rostro de la novia

Termino con la onírica aparición nocturna de Eleonora. De modo obsesivo, alucinatorio, la imagen de la misteriosa novia se proyecta en un muro imaginario. Con algunas variaciones, reaparece el isotropismo siguiente:

*Y por mi espíritu esbaló, [...] en un anochecimiento lejano, el semblante de imploración de la amada niña, inmóvil junto al álamo negro (I, 35).

*Dulcemente, como una sombra en un muro blanqueado de luna, pasó toda ella, y en cierto anochecimiento lejano vi el semblante de imploración de la niña inmóvil junto al álamo negro (III, 80).

*Lentamente, como en un muro blanqueado de luna, pasó por mis ojos el semblante de imploración de la niña inmóvil junto a la verja negra (III, 90). 
En este conjunto semiótico, se repiten, redistribuidos, los mismos conceptos fundamentales: la blancura (el muro-pantalla del cine imaginario que se fabrica el protagonista), la oscuridad, la lejanía, el sufrimiento, la inmovilidad.

\subsection{Un neodiscurso liberador}

De este último ejemplo se pueden sacar unas conclusiones. Si la reiteración de la estructuración le confiere un estatuto de estereotipo plagiable y autoplagiable, los deslizamientos observados en las variantes constituyen resquicios de libertad. Además, el conjunto hace aparecer un texto semiótico, el de la ausencia/presencia, que define la prestigiosa aura baudelairiana. Esta nueva expresión del tópico de la separación de los amantes ya está lejos del tratamiento aparatoso y sensiblero que le dan los textos tangueros.

Por otra parte, el primer ejemplo citado, el de la arruga (dos personajes distintos convocan la misma estructura), así como hay otros en el texto, nos permite adentrarnos en el funcionamiento textual. La confrontación de prácticas discursivas contradictorias tiene por efecto desestabilizar las formas y los conceptos. Así descontextualizados, los nuevos clichés se autonomizan, lo que les permite circular libremente para entrar en diversas configuraciones y participar, de este modo, en el proceso de producción del sentido.

\section{Conclusión. Estereotipo y transgresión: irrupción de la moderni- dad en la Argentina de la década de 1920}

\section{Una operación biogenética}

Uno de los mayores intereses del estudio de los fenotextos que se manifiestan en relación con la incorporación en el texto arltiano de todo ese material desclasado de la paracultura, es que ofrece la posibilidad al analista de observar el texto en gestación ${ }^{23}$.

23. Esta primera conclusión se basa en los avances teóricos y metodológicos propuestos por Edmond Cros en De l'engendrement des formes (Montpellier: CERS, 1990) 20-22 y passim. 
El fenómeno textual que se acaba de estudiar se podría definir, en primer lugar, como una operación biológica. Los conceptos utilizados de amalgama, metabolización, aglutinación de los elementos absorbidos por el texto no tienen nada casual; no han de entenderse en sentido metafórico sino propio, ya que describen un proceso de morfogénesis textual, que responde a unas leyes de programación, las cuales presentan una exacta homología con las que rigen los fenómenos observados en las ciencias físicas y biológicas.

Las huellas del arqueodiscurso localizadas por el análisis actúan en $E J R$, no como materiales pasivos, sino al contrario como elementos genéticos positivos que dinamizan la escritura y participan activamente en la morfogénesis.

\section{Un gesto rupturista}

En la Argentina de la tercera década del siglo XX, esta primera novela de R.A. no sólo funda la narrativa urbana rioplatense, sino que inaugura una nueva práctica literaria sin précedentes en la región.

\subsection{Desjerarquización de los niveles y mezcolanza argentina}

La heterogeneidad interdiscursiva, en la que hemos hecho hincapié a lo largo del análisis, transcribe la sociabilidad del texto, y lo articula con la sociedad porteña contemporánea, donde la mezcolanza y el cosmopolitismo son rasgos específicos ${ }^{24}$. En este sentido, la pareja conceptual heterogeneidad/integración, en permanente confrontación tanto en el texto como en la sociedad argentina coetánea, asume una función de ideosema.

Pulverizando las jerarquías consagradas, el texto realiza un histórico gesto de ruptura al incorporar ese otro discurso descalificado,

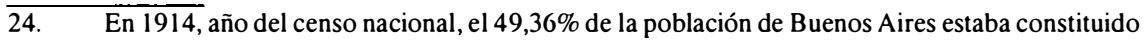
de inmigrantes europeos (italianos y españoles en su mayoría, ruso-polacos, franceses, entre otros). 
intolerable, que se define en términos de carencia. En el contexto argentino, la reescritura del tango (que, desde otro lugar ideológico, realizará también Borges), es una de las claves de decodificación de la formación sociodiscursiva textual en su relación con la de la sociedad argentina. La capacidad de este producto subcultural de aglutinar retóricas, lenguajes e imaginarios de la clase media hace del tango un modelo emblemático, uno de los núcleos constitutivos de la mitología urbana bonaerense, en la que la primera novela de R.A. va también a participar.

\subsection{Subversión de la función reaccionaria del arqueodiscurso}

Las tensiones y contradicciones generadas por el dialogismo entre los sistemas culto/popular, transcriben conflictos cuyo origen hay que buscar en la sociedad contemporánea de la escritura. Producido en el medio de la pequeña burguesía porteña oriunda de la emigración, el texto marca una ruptura con la estrategia de ocultación de su estrato social que el voluntarismo optimista de esta clase mayoritaria desarrollaba desde los prometedores principios de siglo en la Argentina de la opulencia, pero que la crisis que se está instalando, al amenazar el consenso social, hace ya caducar.

Es significativo que su publicación en 1926 haya causado un choque y suscitado el rechazo, no sólo de la institución literaria dominada por los conservadores, que lo justificaba en nombre de criterios normativos-técnicos (se decidió en las camarillas que R.A. escribía mal y componía aún peor), sino también del propio medio social del escritor. En efecto, en EJR se desenmascara la realidad disimulada dolorosamente: la alienación, la adhesión a falsos modelos de identificación, las frustraciones sociales y sexuales, los sueños compensatorios y el lenguaje cursi y desfasado de novelita rosa. El texto of recía al medio pelo ${ }^{25}$ argentino un espejo en el que no quería

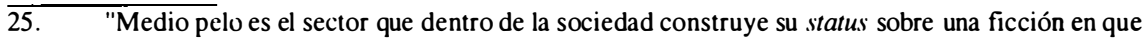
las pautas vigentes son las que corresponden a una situación superior a la suya, que es la que quiere simular" (Arturo Jaurctche, El medio pelo en la sociedad argentina, 13a. ed. Buenos Aires: A. Peña Lillo editor, 1976) 19. 
verse, prefiriendo refugiarse en el mimetismo ilusionado y consolador del tango. A otro nivel literario, los sainetes grotescos de Armando Discépolo presentan el mismo discurso subversivo de una minoría que, desde su propio terreno, toma conciencia de sus carencias y mentiras.

\subsection{Modernidad y emancipación: un texto de la transgresión}

Las tensiones percibidas en el funcionamiento textual/intertextual en relación con la reescritura del arqueodiscurso (dialéctica del mimetismo y del distanciamiento paródico) transcriben la inseguridad de la situación cultural que vivía el país. A pesar del fructuoso debate sobre el futuro de la literatura argentina que, en la década de 1920, suscitó el enfrentamiento (por supuesto verbal) de los dos grupos que dominaban la vida cultural, los vanguardistas de Florida, capitaneados por Borges y Güiraldes, y los "populistas" comprometidos de Boedo, con los que R.A. sentía más afinidades (las divergencias no excluían los contactos y las mutuas influencias), a pesar del extraordinario desarrollo, único en América Lațina, de la nueva práctica social del consumo libresco por las masas, a raíz de la política de instrucción pública y del auge de la industria editorial, a pesar, pues, de todos esos avances culturales, la literatura quedaba dominada por la tradición conservadora del siglo XIX, cuyos modelos canónicos eran exclusivamente europeos. Al desjerarquizar la cultura, abriéndose a lenguajes y géneros marginados por el sistema elitista, el texto de R.A. realiza un acto de subversión y de ruptura.

En esta nueva escritura transcriptora de las hibridaciones de la sociedad del momento, se está jugando nada menos que la capacidad de la cultura argentina de emanciparse de los modelos neocoloniales y crear sus propios modelos de identificación, para entrar plenamente en la modernidad. La ausencia casi total de referencias a la literatura española contemporánea (caso omiso de la mención de Pío Baroja, que se puede considerar como una huella discursiva del intertexto anarquista) es elocuente. El texto prefiere aproximarse a los prestigiosos 
creadores rusos y franceses del siglo XIX. Entre ellos, Beaudelaire ocupa el lugar preeminente, porque su obra introdujo una verdadera fractura en el curso de la historia literaria, al recuperar la fuerza y la belleza originales de las formas desgastadas por el tiempo y la reprodución mimética. Finalmente, los estereotipos, lejos de desaparecer, alimentan y dinamizan la producción literaria del siglo XIX y del XX nuestro, desde Flaubert y Baudelaire hasta Boris Vian e Ionesco, desde Arlt hasta Cortázar y Manuel Puig. La gran paradoja que encierran las obras tanto de Baudelaire como de Arlt, es que crearon una literatura de la transgresión con escorias del pasado, en un ejercicio mimético de referencia al discurso más desprestigiado y conservador. Por ello, sus textos se convierten en un espacio de reconciliación de culturas antagónicas.

Para concluir, observaremos que si el texto de EJR secretó nuevos estereotipos, su publicación originó, a su vez, un nuevo tópico, el de la "mala escritura" de su autor, tantenazque por los años 60 había unos críticos, al parecer desfasados, que lo cultivaban todavía ${ }^{26}$.

26. Es el caso de Enrique Anderson Imbert que, en 1965, escribía lo siguiente: "[...] Escribía mal, componía mal. [...] El empuje de Arlt tenía, desgraciadamente, graves fallas artísticas". Historia de la literatura hispanoamericana (México: Fondo de Cultura Económica, 1961). 